\title{
Effect of sludge pretreatment on the performance of anaerobic/ anoxic/ oxic membrane bioreactor treating domestic wastewater
}

\author{
${ }^{1}$ J. Rajesh Banu; ${ }^{2}$ D. K. Uan; ${ }^{1}$ S. Kaliappan; ${ }^{3 *}$ I. T. Yeom \\ ${ }^{1}$ Department of Civil Engineering, Anna University of Technology Tirunelveli, Tamilnadu, India \\ ${ }^{2}$ Institute for Environmental Science and Technology, Hanoi University of Technology, Hanoi, Vietnam \\ and Sungkyunkwan University, Suwon, Korea \\ ${ }^{3}$ Department of Civil and Environmental Engineering, Sungkyunkwan University, Suwon, Korea
}

Received 28 June 2010; $\quad$ revised 10 August 2010; accepted 15 December 2010; Available online 1 March 2011

\begin{abstract}
In the present study, two bench-scale anaerobic/ anoxic/ oxic submerged membrane bioreactors were used to study the effect of thermochemical sludge disintegration system on the excess sludge production. Among the two membrane bioreactors, one was named experimental membrane bioreactor and another one was named as control membrane bioreactor, where a part of the mixed liquor was treated with thermo chemical and was returned back to membrane bioreactor. Thermo chemical digestion of sludge was carried out at fixed $\mathrm{pH}(11)$ and temperature $\left(75^{\circ} \mathrm{C}\right)$ for $24 \%$ chemical oxygen demand solution. The other one was named control membrane bioreactor and was used as control. The reactors were operated at three different mixed liquor suspended solids range starting from $7500 \mathrm{mg} / \mathrm{L}$ to $15000 \mathrm{mg} / \mathrm{L}$. Both of membrane bioreactors were operated at a flux of $17 \mathrm{LMH}$ over a period of 240 days. The designed flux was increased stepwise over a period of one week. During the 240 days of reactor operation, both of membrane bioreactors maintained relatively constant transmembrane pressure. The sludge digestion had no impact on chemical oxygen demand removal efficiency of the reactor. The results based on the study indicated that the proposed process configuration has potential to reduce the excess sludge production as well as it didn't deteriorate the treated water quality.
\end{abstract}

Keywords: Membrane bioreactor; Sludge reduction; Thermochemical pretreatment; Transmembrane pressure

\section{INTRODUCTION}

During operation of biological wastewater treatment processes, a part of activated sludge should be withdrawn and disposed in order to maintain appropriate level of biomass concentration in the reactor. The expense for the treatment of the excess sludge has been estimated to be as much as $50-60 \%$ of the total expense of wastewater treatment plant (Nowak, 2006; Hooshyari et al., 2009; Pasztor et al., 2009; Rajesh banu et al., 2009; Zhang et al., 2009). Recently various sludge disintegration techniques have attracted attentions as promising alternatives to reduce sludge production. Among these, thermal and chemical treatments were mostly widely studied and adopted in many commercialized processes. In these studies a part of the recycled sludge was pretreated and was returned to the wastewater stream for further

$\bar{\triangle}$ *Corresponding Author Email: yeom@skku.edu
Tel./Fax: +944 421554 biodegradation. In overall, the basis for the sludge reduction process is an effective combination of the methods for sludge disintegration and biodegradation of the treated sludge (Rajesh banu et al., 2008; Liu et al., 2010; Cheng et al., 2011). Introduction of sludge disintegration into other wastewater treatment processes such as membrane bioreactor (MBR) may also be an interesting approach. The membrane processes are characterized by immersing the membrane modules as solid liquid separation units directly in the aerobic basin, were developed for wastewater treatment (Yamamoto and Win, 1991; Goyal et al., 2008; Xia et al., 2008). MBR process has been known as a process with relatively high decay rate and less sludge production due to much longer biomass retention in the reactor.

The present study utilizes the advantages of both MBR and sludge pretreatment process for the reduction 
of excess sludge. The objectives of this study were to evaluate the effects of sludge disintegration on the rate of sludge production and the performance of MBR. Combined treatment of alkali and temperature were tested for sludge pretreatment. In this scheme, alkaline treatment serves not only as a sludge solubilizing reagent but also act as a buffering agent to prevent $\mathrm{pH}$ drop. The major experimental part of the study was carried out at Department of Civil and Environment Engineering, Sungkyunkwan University, Korea for a period of 8 months and during the study period, the performance of the reactor was evaluated by comparing it with control reactor.

\section{MATERIALS AND METHODS}

\section{Wastewater}

The primary settled domestic wastewater from Sungkyunkwan University, Korea was used as a feed for the present study. The characteristics of the primary settled wastewater were given in the Table 1.

\section{A2O - MBR}

The working volume of the reactor anaerobic/ anoxic/oxic-membrane bioreactor (A2O-MBR) was 83.4 L. A baffle was placed inside the reactor to divide it into anaerobic $(8.4 \mathrm{~L})$ anoxic $(25 \mathrm{~L})$ and aerobic basin $(50 \mathrm{~L})$. The wastewater was fed into the reactor at a flow rate of $8.4 \mathrm{~L} / \mathrm{h}(\mathrm{Q})$ using a feed pump. A liquid level sensor, planted in aerobic basin of A2O-MBR controlled the flow of influent. The hydraulic retention time (HRT) of anaerobic, anoxic and aerobic basin was 1, 3 and 6 h, respectively. In order to facilitate nutrient removal the reactor was provided with two internal recycle (IR). IR1 connects anoxic and anaerobic and IR $2(Q=3)$ was between aerobic and anoxic. Anaerobic and anoxic basins were provided with low speed mixer to keep the mixed liquid suspended solids (MLSS) in suspension. Dissolved oxygen (DO) concentration in the aerobic basin was maintained at $3.5 \mathrm{mg} / \mathrm{L}$ and was monitored continuously through online DO meter. The solid liquid separation happens in an aerobic basin with the help of the membrane. Five flat sheet types of membranes with the pore size of $0.23 \mu \mathrm{m}$ were used for the study. The characteristic features of the membranes used were given in the Table 2.

A common tube which interns connected to a suction pump connected the each module. A provision was made in the common tube to measure the transmembrane pressure (TMP) during suction. The suction pump was operated in sequence of timing, which consists of 10 min switch on, and 2 min switch off.

\section{Thermo-chemical digestion of sludge}

MLSS from aerobic basin of MBR was withdrawn at the ratio of $1.5 \%$ of $\mathrm{Q} /$ day and subjected to thermo chemical digestion. Thermo chemical digestion was carried out at the fixed $\mathrm{pH} 11(\mathrm{NaOH})$ and temperature $\left(75^{\circ} \mathrm{C}\right.$ ) for $3 \mathrm{~h}$. Besides acting as a solubilisation agent the added alkali sodium hydroxide can serve as a neutralizing agent of solubilised biomass and act as an alkalinity supplement during nitrification. It is also possible that the solublised biomass can be subjected to anaerobic degradation and the resulting fuel gas can be used for sludge pretreatment.

Table 1: Characteristics of the wastewater

\begin{tabular}{lcccccc}
\hline Unit $(\mathrm{mg} / \mathrm{L})$ & TCOD & SCOD & SS & TN & TP & Alkalinity \\
\hline Average & 190 & 130 & 66 & 35 & 4.5 & 165 \\
Standard Deviation & 42 & 22 & 12 & 6 & 1 & 20 \\
\hline
\end{tabular}

Table 2: Characteristics of the membrane used

\begin{tabular}{ll}
\hline Parameters & Value \\
\hline Pore size & $0.22 \mu \mathrm{m}$ \\
Material & Polyvinylidene fluoride \\
Area & $0.1 \mathrm{~m}^{2} /$ module \\
Dimension & $24 \mathrm{~cm} \times 34 \mathrm{~cm} \times 10 \mathrm{~cm}$ \\
\hline
\end{tabular}




\section{Chemical analysis}

Chemical oxygen demands (COD), MLSS, mixed liquor volatile suspended solids (MLVSS) of the raw and treated wastewater were analyzed following methods detailed in APHA et al., (2005). The analysis of extra polymeric substances (EPS) in biomass was made through a thermal extraction method. The mixed liquor was centrifuged (4000 rpm for $20 \mathrm{~min}$ ) in order to remove the soluble EPS from bound EPS. After collecting the soluble EPS, the remaining pellet is washed and resuspended in saline water $(0.9 \% \mathrm{NaCl}$ solution). The extracted solution was then separated from the sludge solids by centrifugation under similar condition (4000 rpm for $20 \mathrm{~min}$ ), the supernatant obtained at this stage were being referred to as bound EPS solution. The EPS solution was then measured in terms of protein and carbohydrate contents by Lowry method with bovine serum albumin (BSA) as standard (Lowry et al., 1951) and by phenolic-sulfuric acid method with glucose as standard (Dubois et al., 1956) respectively. The sum of protein and carbohydrate represented the total EPS content.

\section{RESULTS AND DISCUSSION}

Fig. 1 presents data of MLSS profile during 240 days period of reactor operation. One of the advantages of MBR reactor was it can be operated in high MLSS concentration. The reactor was seeded with enhanced biological phosphorous removal (EBPR) sludge from the Kiheung, sewage treatment plant, Korea. Both the reactors were startup with the MLSS concentration of $5700 \mathrm{mg} /$ L. MLSS starts to increase steadily with increase in period of reactor operation and reached a value of $7200 \mathrm{mg} / \mathrm{L}$ on day 40 . From then onwards, MLSS concentration was maintained to the desired range of $7500 \mathrm{mg} / \mathrm{L}$ (Run 1). At the end of 60 day stable period of reactor operation, a part of MLSS was withdrawn at a rate of $1.5 \% \mathrm{Q} /$ day and subjected to be thermochemical treatment. Run II was initiated on day 120 by not withdrawing excess sludge. As a result of that, MLSS began to accumulate in the system and reaches a value of $10400 \mathrm{mg} / \mathrm{L}$ for EMBR and $10600 \mathrm{mg} / \mathrm{L}$ for CMBR on day 130. From then onwards sludge withdrawal

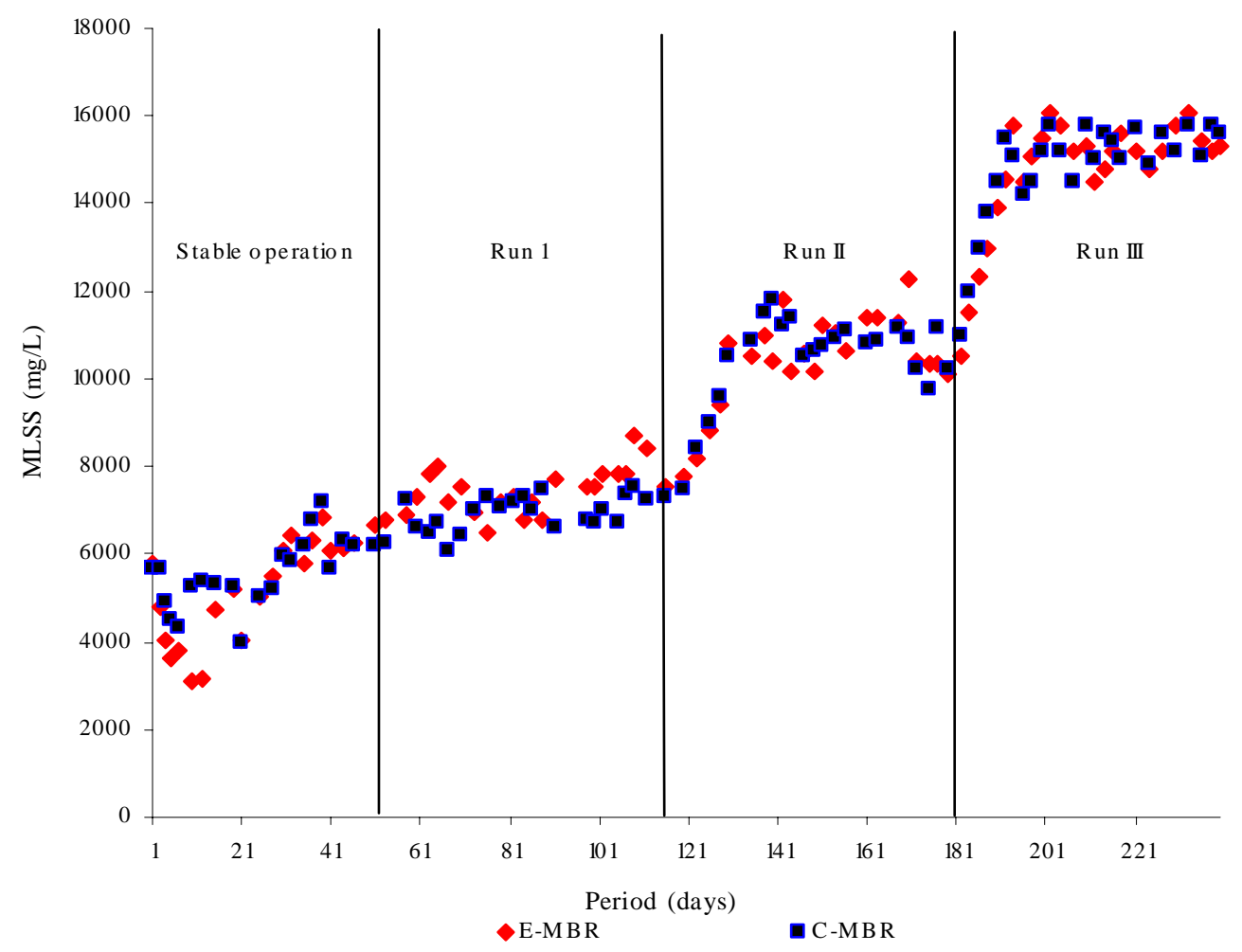

Fig. 1: MLSS profile during the period of study 


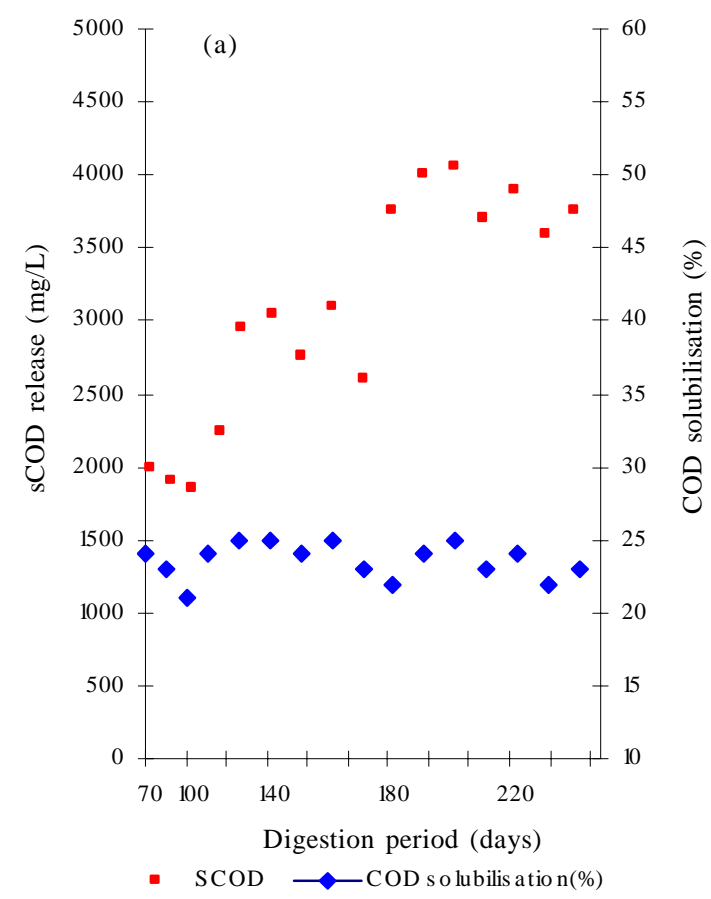

Fig. 2: Effect of thermochemical digestion on mixed liquor solubilisation (a) and pH (b)

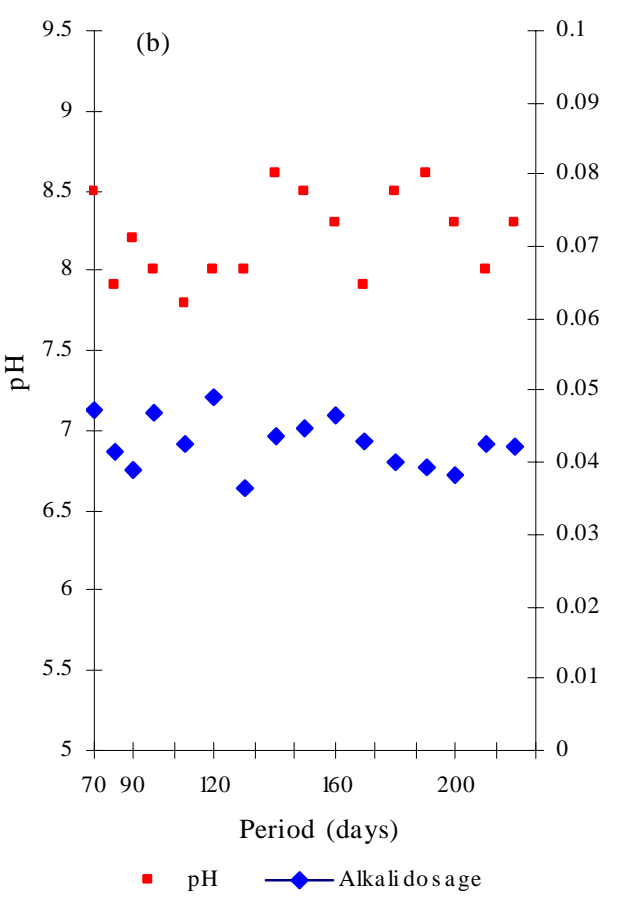

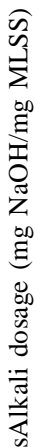

was again initiated and MLSS was maintained around $11000 \mathrm{mg} / \mathrm{L}$. Like wise Run III was initiated on day 180 and MLSS was maintained in the range of $15000 \mathrm{mg} / \mathrm{L}$.

Fig. 2a depicts the influence of thermochemical treatment on sludge solubilisation and sCOD release. For sludge pretreatment recommended temperature by Vlyssides and Karlis (2004) was used. Whereas the $\mathrm{pH}$ used for sludge disintegration was 11 and was found to be little lower than the optimum value of 12 (Neyens et al., 2003). While working on sludge digestion in aerobic reactor using the combination of ozone and alkali, Young et al. (2007) have reported that the usage $\mathrm{pH} 12$ for sludge disintegration makes the process difficult to maintain $\mathrm{pH}$ inside the reactor between 7 and 8.

Considering the difficulties faced by Young et al. (2007) the present study uses pH 11 instead of 12 . Sodium hydroxide was used as an alkali in the present study. Among the various alkalis tried for chemical hydrolysis, sodium hydroxide was found to be most efficient for inducing cell lysis (Rocher et al., 1999). Alkali added reacts with the cell walls in several ways including saponification of lipids in the cell walls, which leads to solubilisation of membrane. Disruption of sludge cells leads to leakage of intracellular material out of the cell. The soluble COD (sCOD) after digestion was measured and found to be in the range of 1850 to $4050 \mathrm{mg} / \mathrm{L}$. sCOD was found to increase with increase in MLSS concentration subjected to sludge digestion.

The released sCOD can be helpful for denitrification process as it may act as a carbon source if the feed used was a low strength organic wastewater. It is known that solubilisation efficiency was used as an index for the efficiency of sludge disintegration. The solubilisation efficiency was calculated by using the equation formulated by Yeom et al. (2002). The thermo chemical sludge solubilisation efficiency was found to be in the range of 22 to $25 \%$. The presently observed solubilisation value was comparable to values reported by previous workers (Rajesh banu et al., 2008; Uan et al., 2010).

From the Fig. 2b it is clearly evident that an alkali dosage in the range of 0.039 to $0.46 \mathrm{mg} \mathrm{NaOH} / \mathrm{mg}$ MLSS was required to achieve an average COD solubilisation efficiency of $24 \%$. This dosage was equivalent to 350 to $420 \mathrm{mg} / \mathrm{L}$ of $\mathrm{NaOH}$. Whereas, researchers working on sludge pretreatment using alkali $\mathrm{NaOH}$ alone, 


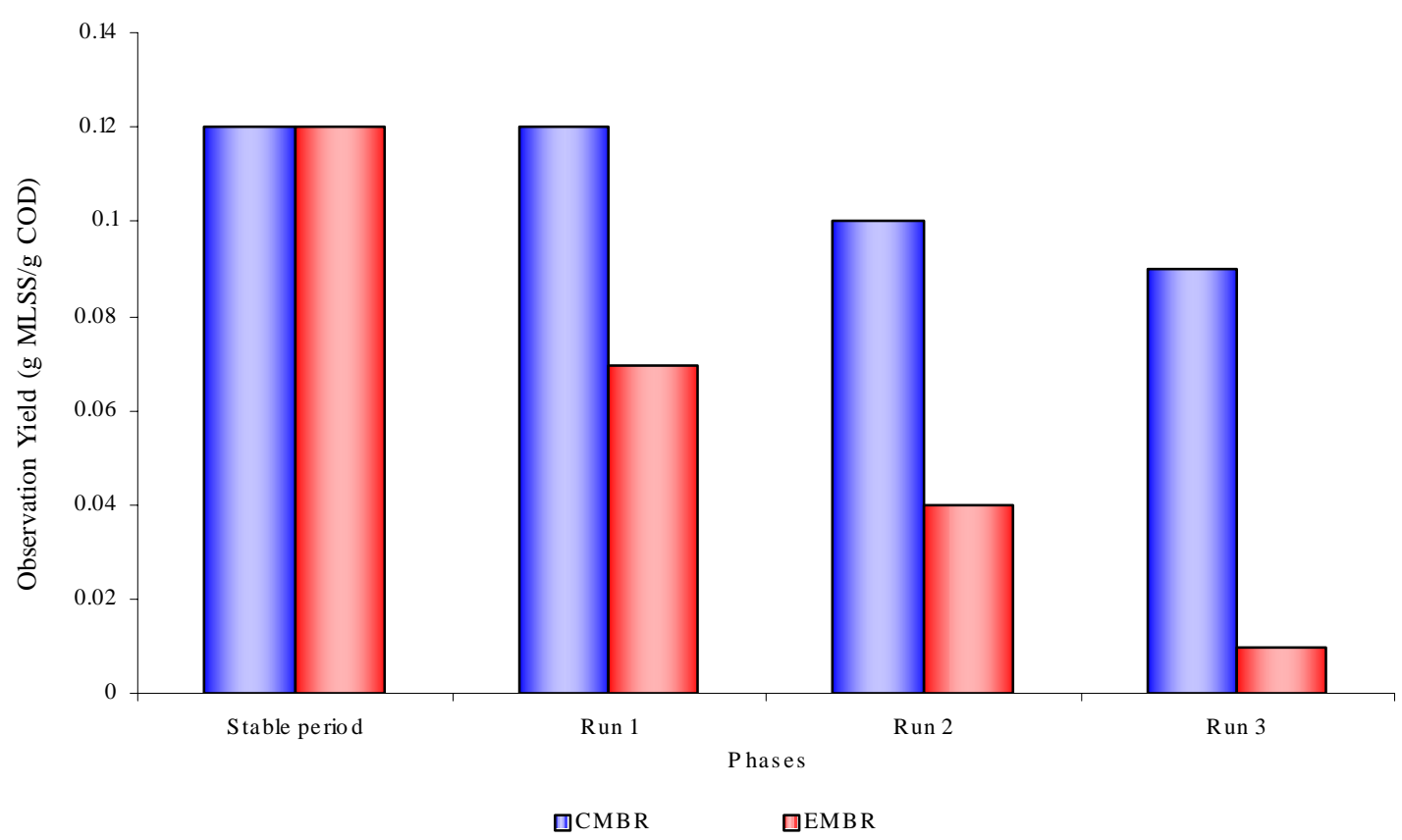

Fig. 3: The average observed yield during the period of study

required an alkali dosage of around $2 \mathrm{~g} / \mathrm{L}$ to achieve 24 $\%$ sludge solubilisation (Kim et al., 2003). From that it is evident that the combination of thermal and alkali sludge pretreatment could reduce the considerable amount of alkali usage. This will help in significant decrease of total treatment cost. Another advantage of thermochemical combination is that, the added alkali serves as a neutralizing agent to buffer the $\mathrm{pH}$ drop due to the sludge solubilisation. The other methods of sludge disintegration techniques such as acid ozone, and thermal produce solubilised sludge with acidic $\mathrm{pH}$ (Kim et al., 2003) and it require further buffering before it reintroduced for successive treatment. The $\mathrm{pH}$ of the solubilised sludge was found to be in the range of 8 to 9.5. This slight alkaline solution can also be used to buffer $\mathrm{pH}$ loss in $\mathrm{A} 2 / \mathrm{O}$ reactor during nitrification process. In overall, the combination of alkali and thermal treatment appears to be effective in reducing the alkali cost as well as controlling the $\mathrm{pH}$ in the reactor.

The observed yields (Yobs) for control membrane bioreactor (CMBR) and experimental membrane bioreactor (EMBR) were calculated and presented in Fig. 3. The average Yobs for the stable period was found to be 0.12 gMLSS/gCOD for both CMBR and EMBR. The presently observed Yobs value was comparatively lowers than a value of 0.4 gMLSS/gCOD reported for the conventional activated sludge processes (Metcalf and Eddy, 2003). The difference in observed yield of these two systems is due to its working MLSS concentration. The thermo chemical sludge pretreatment was started on day 60 for EMBR. CMBR was used as a control to study the effect of sludge pretreatment on sludge production.

Fig. 5 explains data on average Yobs for the three different phases namely run I, II and III. These phases demonstrate the role of sludge disintegration in controlling the excess sludge production. The Yobs for run I was found to be 0.12 gMLSS/gCOD for CMBR and 0.07 gMLSS/gCOD for EMBR, respectively. It is interesting to note that the Yobs for CMBR was also start to decrease from 0.12 to 0.09 gMLSS/gCOD when MLSS was increased from 7500mg/L (Run I) to 15000 $\mathrm{mg} / \mathrm{L}$. The decrease in Yobs with increase in MLSS concentration is attributed to low biomass production at high MLSS concentration. (Visvanathan et al., 2000). In the case of EMBR, the observed yield for run III was found to be lower than its previous two runs, namely I and II. The Yobs for run III, II and I were found to be $0.01,0.04$ and $0.07 \mathrm{gMLSS} / \mathrm{gCOD}$, respectively. This is due to the fact that at run III, 


\section{J. Rajesh Banu et al.}

more amounts of biosolids were subjected to be sludge digestion and also due to low biomass production at high solid concentration.

The daily sludge production was calculated by following methods detailed in Uan et al. (2009). By summing up the daily sludge production during the study period, the total accumulated daily sludge production (DSP ${ }_{\text {accumulated }}$ ) was calculated.

$$
D S P_{\text {accumulated }}=\sum_{\text {day }=1}^{i} D S P_{d a y}
$$

Graphic representations of daily accumulated sludge versus the three different runs were presented in Fig. 4. During the initial period of stable operation solid production for EMBR and CMBR was nearly the same. At run I the solid production for EMBR and CMBR accounts for 195 SS/g and 323 SS/g, respectively. This accounts for $39.5 \%$ of sludge reduction and was calculated from the graph. Similar to our study working on sludge reduction in activated sludge process, Rocher et al. (1999) have reported about $30 \%$ sludge reduction. The total amount of sludge accumulated for run II and III were found to be 159 and $116 \mathrm{SS} / \mathrm{g}$ for CMBR and 64 and $33 \mathrm{SS} / \mathrm{g}$ for EMBR. From the data, it is evident that, when compared to CMBR, the EMBR reduced 60 and

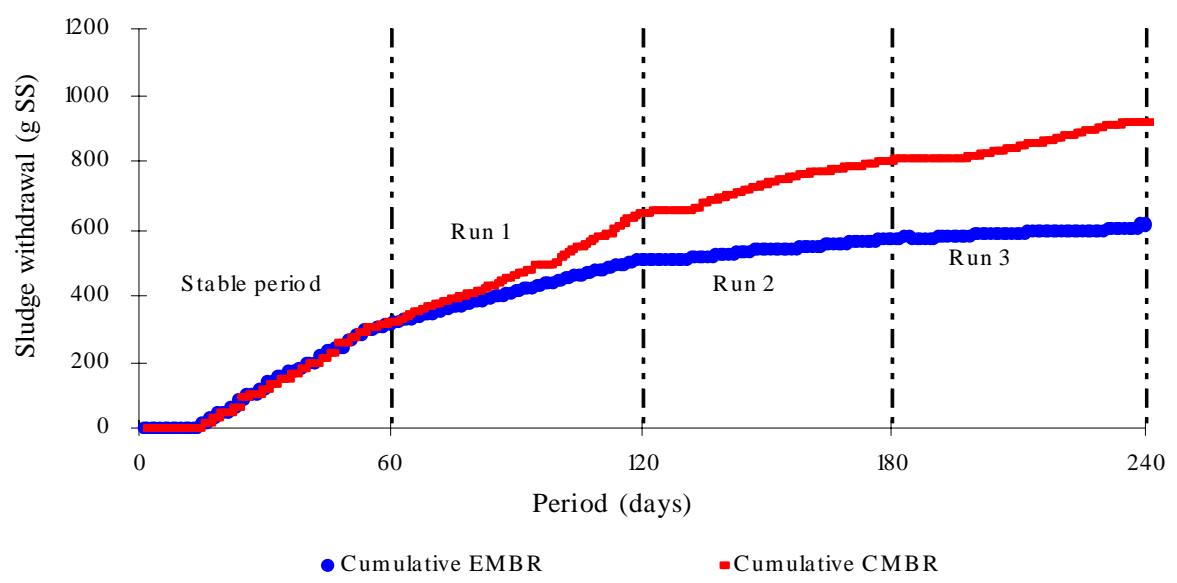

Fig. 4: Daily sludge production in MBRs during the period of study
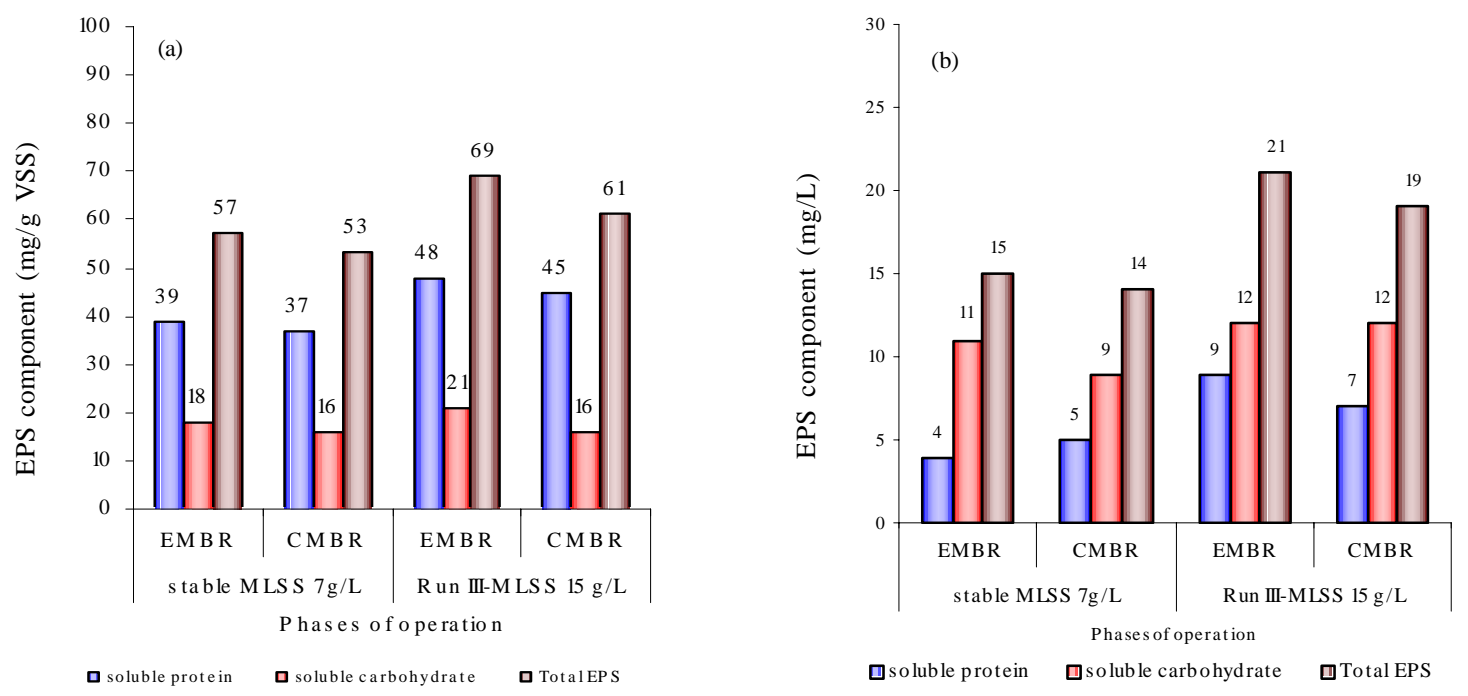

Fig. 5: EPS profile of the MBRs during the period of study 


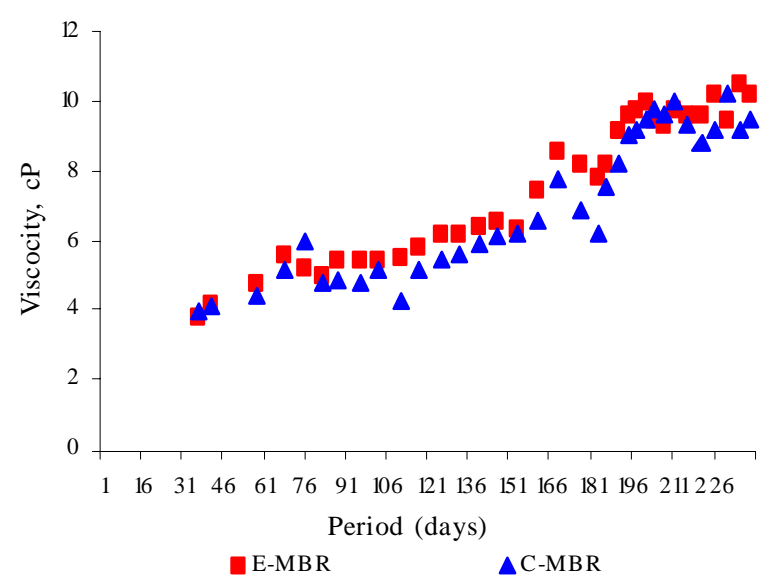

Fig. 6: Variation of viscosity in MBRs during the period of study

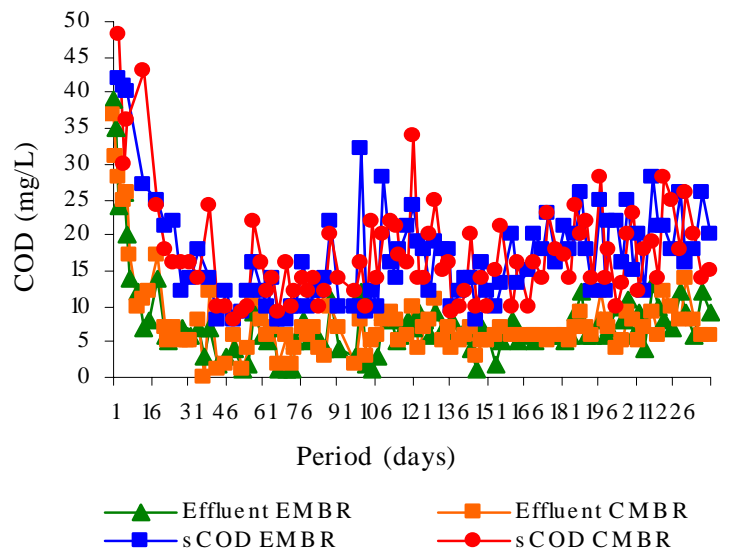

Fig. 8: Variation of COD profile in aerobic basin and effluent of MBRs

$72 \%$ of the total amount of sludge for run II and III, respectively.

EPS is one of the principle components responsible for biofouling of membrane (Kelly et al., 1993). Fig. 5a and $b$ show the bound and soluble EPS components for EMBR and CMBR. The amount of total bound EPS was found to be higher at run III for both the MBRs. At run III both the MBR were operated with high MLSS and this may be the reason for elevated bound EPS at higher MLSS concentrations. The main source for soluble EPS (sEPS) in mixed liquor is Abiomass decay and cell lysis. The high concentration of sEPS led to

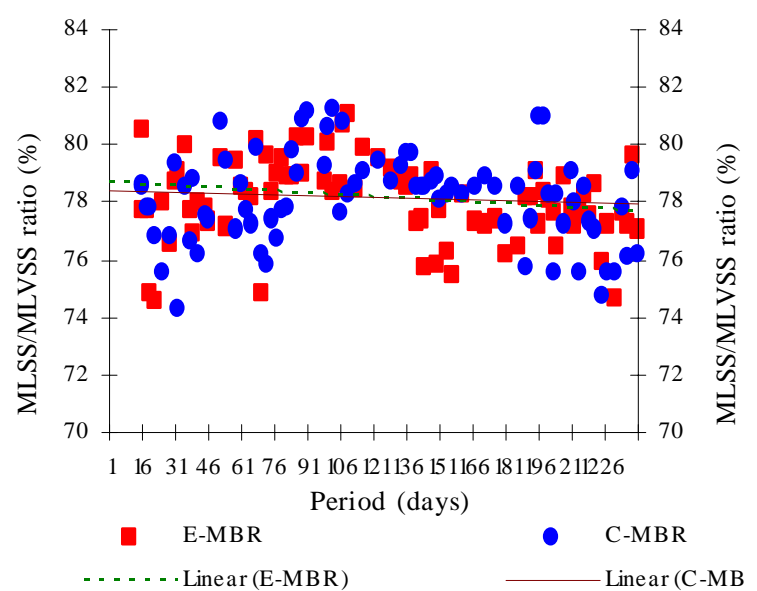

Fig. 7: MLSS/MLVSS profile of MBRs during the period of study

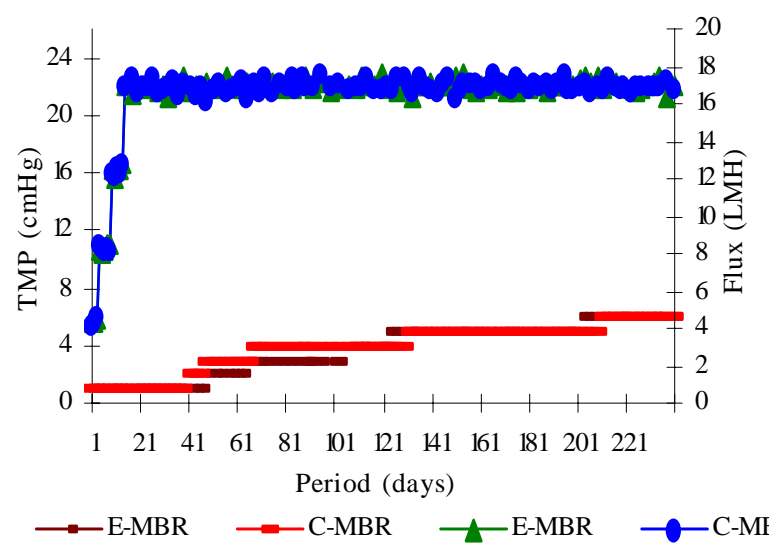

Fig. 9: Variation of TMP during the study period of MBRs

hydrophobic sludge and was attributed membrane fouling by adsorption, a specific interaction between protein and membrane and by deposition during filtration (Sombatsompop et al., 2006). It is believed that cell lysis by sludge pretreatment increases the sEPS concentration of the mixed liquor. In this study, it was found that the soluble protein concentration of CMBR (19 mg/L) and EMBR (21 mg/L) was nearly the same at the end of run III. From the finding it can be concluded, that in EMBR the released sEPS was degraded and there is no buildup of sEPS. Viscosity of the mixed liquor plays a major role in limiting the oxygen transfer and 
foul MBR system (Wei et al., 2009). EPS can increase the viscosity of the liquids (Stal and Brouwer, 2003). In the present study there is no significant difference between the viscosities of both MBRs (Fig.6) through out the operational period. Viscosity of both reactors increases with increase in MLSS concentration. It is known that increase in MLSS concentration can increase the viscosity (Visvanathan et al., 2000). It appears that the sludge disintegration system does not increase the viscosity of the mixed liquor and presumably its fouling potential.

From the Fig. 7 it is clearly evident that the volatile fraction of the mixed liquor solids in C-MBR and EMBR are almost identical in the range of 75 to $80 \%$. Most of the inorganic fraction of the degraded cells did not accumulate in the reactor and presumably permeated through the membrane as ionic species. Similar to our study, while Aon sludge recycling in aerobic MBR reactor treating domestic wastewater Young et al. (2007) have reported, that there is no change in volatile fraction of the mixed liquor before and after the sludge pretreatment.

In contrast to our study Yasui et al. (1996) have reported a decrease in MLSS/MLVSS ratio by $10 \%$ for MBR treating pharmaceutical wastewater over a period of 9 months. It may be due to the characteristics of wastewater and not due to the sludge pretreatment process as pharmaceutical wastewater contain lot of inorganic substances. In that case, the extent of inorganic accumulation may not depend upon the inorganic substances released from disintegrated cells. The observation in this study strongly indicates that most of the inorganic from the disintegrated cells do not accumulate in the reactor as particles.

Fig. 8 shows variation in COD removal efficiency of A2O-MBR reactor during the study period. It is evident from the figure that, the COD removal efficiency of A2O system remains unaffected before and after the introduction of sludge reduction practices. A t-test analysis showed that the differences between EMBR and CMBR are not statistically significant. However, it has been reported that, in wastewater treatment processes including disintegration-induced sludge degradation, the effluent water quality is slightly detoriated due to the release of nondegradable substances such as soluble microbial products (Yasui et al., 1994; Sakai et al., 1997; Yoon et al., 2004). The COD removal increased with increase in time during the initial phases of reactor operation and it attains steady state on day 19. From then onwards, the COD removal was in the range of 96-98 $\%$ (calculated from the graph). During stable operational period, the sCOD concentration in the aerobic basin of MBRs was found to be 12 to $32 \mathrm{mg} /$ $\mathrm{L}$ for EMBR and 14 to $36 \mathrm{mg} / \mathrm{L}$ for CMBR respectively. Corresponding organic concentration in the effluent was varied from 2 to $14 \mathrm{mg} / \mathrm{L}$ for EMBR and 2 to 16 $\mathrm{mg} / \mathrm{L}$ for CMBR respectively. From that, it can be concluded that the membrane separation played an important role in providing the excellent and stable effluent quality.

The suction pump was started after the first week of seeding and was based on the SCOD of the aerobic basin. The pump was started when sCOD in the aerobic basin was $35 \mathrm{mg} / \mathrm{L}$. The designed flux for the membrane was $17 \mathrm{LMH}$. This was achieved by stepwise increase of flux from $25 \%$ to $100 \%$ over a period of three weeks.

Fig. 9 shows the transmembrane pressure (TMP) variation during the operational period. A sudden change in TMP is an indicator of membrane fouling (Hassani et al., 2008). It indicates that, transmembrane pressure increased slowly over a period of 240 days. At the end of 240 days of reactor operation, the TMP was found to be $6 \mathrm{cmHg}$. It appears that the sludge disintegration system does not play role in membrane fouling.

Similar to our study, while working on sludge reduction practices in MBR, Young et al. (2007) have reported that, the alkaline treatment of sludge didn't cause membrane fouling. From the above findings, it can be concluded that, stable operation of MBR process was possible without significant accumulation of biomass when a part of the biological solids were disintegrated with alkali at $\mathrm{pH} 11$ and temperature at 75 ${ }^{\circ} \mathrm{C}$. The TMP was maintained less than $6 \mathrm{cmHg}$, indicating no significant occurrence of membrane fouling. There is no increase in effluent COD concentration after the introduction of sludge pretreatment. It appears that the solubilized fraction of the mixed liquor obtained by the chemical sludge disintegration might be easily biodegraded by other microorganisms. 


\section{CONCLUSION}

It can be concluded, that stable operation of MBR process was possible without significant accumulation of biomass when a part of the biological solids were disintegrated with alkali at $\mathrm{pH} 11$ and temperature $75{ }^{\circ} \mathrm{C}$. Thermochemical sludge digestion favors the solubilisation of excess sludge and makes it amenable for further biodegradation. The thermochemical sludge pretreatment resulted in $72 \%$ excess sludge reduction. The system can run for a long period of time with any further detoriation in the effluent COD concentration. There is no significant increase in EPS concentration after the introduction of sludge pretreatment. The TMP maintained less than $6 \mathrm{cmHg}$ indicating no significant occurrence of membrane fouling. Further studies focusing on fate of disintegrated sludge are in progress.

\section{ACKNOWLEDGEEMENTS}

This research was supported by Basic Science Research Program through the National Research Foundation of Korea (NRF) (Grant number: 2010-0008860)

\section{REFERENCES}

APHA; AWWA; WEF, (2005). Standard methods for the examination of water and wastewater. $21^{\text {st }}$ edition. American Public Health Association, American Water Works Association and the Water Environment Federation. Washington DC., USA.

Cheng, B.; Hu, C. W.; Zhao, Y. J., (2011). Effects of plants development and pollutant loading on performance of vertical subsurface flow constructed wetlands. Int. J. Environ. Sci. Tech., 8 (1), 177-186 (10 pages).

Dubois, M.; Gillees, K. A.; Hamilton, J. K.; Rebers, P. A.; Simth, F., (1956). Colorimetric method for determination of sugar and related substances. Anal. Chem., 28 (3), 350-356 (7 pages).

Goyal, P.; Sharma, P.; Srivastava, S.; Srivastava, M. M., (2008). Saraca indica leaf powder for decontamination of $\mathrm{Pb}$ : Removal, recovery, adsorbent characterization and equilibrium modeling. Int. J. Environ. Sci. Tech., 5 (1), 27-34 (8 pages).

Hassani, A. H.; Mirzayee, R.; Nasseri, S.; Borghei, M.; Gholami, M.; Torabifar, B., (2008). Nanofiltration process on dye removal from simulated textile wastewater. Int. J. Environ. Sci. Tech., 5 (3), 401-408 (8 pages).

Hooshyari, B.; Azimi, A.; Mehrdadi, N., (2009). Kinetic analysis of enhanced biological phosphorus removal in a hybrid integrated fixed film activated sludge process. Int. J. Environ. Sci. Tech., 6 (1), 149-158 (10 pages).

Kelly, S. T.; Opong, W. S.; Zydney, A. L., (1993). The influence of protein aggregates on the fouling of micro filtration membrane during stirred cell filtration. J. Membrane Sci., 80 (1), 175-187 (14 pages).
Kim, J.; Park, C.; Kim, T. H.; Lee, M.; Kim, S.; Kim, S. W.; Lee, J., (2003). Effects of various pretreatments for enhanced anaerobic digestion with waste activated sludge. J. Biosci. Bioeng., 95 (3), 271-275 (5 pages).

Liu, R. R.; Tian, Q.; Yang, B.; Chen, J. H., (2010). Hybrid anaerobic baffled reactor for treatment of desizing wastewater. Int. J. Environ. Sci. Tech., 7 (1), 111-118 (8 pages).

Lowry, O. H.; Resebrough, N. J.; Farr, A. L.; Randall, R., (1951). Protein measurement with the folin phenol reagent. J. Biol. Chem., 193 (1), 265-275 (11 pages).

Metcalf; Eddy., (2003). Wastewater engineering treatment and reuse. $4^{\text {th }}$ Ed, Mc Graw Hill publication, New York, USA.

Neyens, E.; Baeyens, J.; Creemers, C., (2003). Alkaline sludge hydrolysis. J. Hazard. Mater., 97 (1-3), 295-314 (20 pages).

Nowak, Q., (2006). Optimizing the use of sludge treatment facilities at municipal WWTPs. J. Environ. Sci. Health A., 41 (9), 1807-1817 (11 pages).

Pasztor, I.; Thury, P.; Pula, J., (2009). Chemical oxygen demand fractions of municipal wastewater for modeling of wastewater treatment. Int. J. Environ. Sci. Tech., 6 (1), 51-56 (6 pages).

Rajesh banu, J.; Uan, D. H.; Chung, I. J.; Kaliappan. S.; Yeom, I. T., (2009). A study on the performance of a pilot scale A2/0-MBR system in treating domestic wastewater. J. Environ. Biol., 30 (6), 959-963 (5 pages).

Rajesh banu, J.; Uan, D. H.; Yeom, I. T., (2008). Municipal sludge reduction and management using sodium hydroxide and Lime Treatment. In IWA conference, Tamil nadu, India, 5-9 Feb. Coimbatore.

Rajesh banu, J.; Uan, D. H.; Yeom, I. T., (2009). Nutrient removal in an A2O-MBR with sludge reduction. Bioresource Tech., 100 (16), 3820-3824 (5 pages).

Rocher, M.; Goma, G.; Begue, A. P.; Louvel, L.; Rols, J. L., (1999). Towards a reduction in excess sludge production in activated sludge processes: Biomass physicochemical treatment and biodegradation. Appl. Microbiol. Biotech., 51 (6), 883-890 (8 pages).

Sakai, Y.; Fukase, T.; Yasui, H.; Shibata, M., (1997). An activated sludge process without excess sludge production. Water Sci. Tech., 36 (11), 163-170 (8 pages).

Sombatsompop, K.; Visvanathan, C.; Aim, B. R., (2006). Evaluation of biofouling phenomenon in suspended and attached growth membrane bioreactor system. Desalination, 201 (1-3), 138-149 (12 pages).

Stal, L. J.; Brouwer, F. C., (2003). Biofilm formation by benthic diatoms and their influence on the stabilization of inertial mudflats. Berichte-Forschungszentrum Terramare, 12, 109111 (3 pages).

Uan, D. H.; Nguyen, T. T.; Rajesh banu, J.; Kyeongjin, K.; Heo, J.; Yeom, I. T., (2010). Effects of thermochemical pretreatment on the biodegradability of sludge from a biological wastewater treatment system. Maejo Int. J. Sci. Tech., 4 (2), 250-260 (11 pages).

Uan, D. H.; Rajesh banu, J.; Chung, I. J.; Yeom, I. T., (2009). Effect of thermochemical sludge pretreatment on sludge reduction and on performances of anoxic-aerobic membrane bioreactor treating low strength domestic wastewater. J. Chem. Tech. Biotech., 84 (9), 1350-1355 (6 pages).

Visvanathan, C.; Aim, B. R.; Parameshwaran, K., (2000). Membrane separation bioreactors for wastewater treatment. Crit. Rev. Environ. Sci. Tech., 30 (1), 1-48 (48 pages). 
Vlyssides, A. G.; Karlis, P. K., (2004). Thermal alkaline solubilisation of waste activated sludge as a pretreatment stage for anaerobic digestion. Bioresour. Tech., 91 (2), 201-208 (8 pages).

Wei, A. L.; Zeng, G. M.; Huang, G. H.; Liang, J.; Li, X. D., (2009). Modeling of a permeate flux of cross-flow membrane filtration of colloidal suspensions: A wavelet network approach. Int. J. Environ. Sci. Tech., 6 (3), 395-406 (12 pages).

Xia, S.; Guo, J.; Wang, R., (2008). Performance of a pilot scale submerged membrane bioreactor (MBR) in treating bathing waste water. Bioresour. Tech., 99 (15), 6834-6843 (10 pages).

Yamamoto, K.; Win, H., (1991). Tannery wastewater treatment using a sequencing batch membrane reactor. Water Sci. Tech., 23 (7-9), 1639-1648 (10 pages).

Yasui, H.; Nakamura, K.; Sakuma, S.; Iwasaki, M.; Sakai, Y., (1996). A full scale operation of a novel activated sludge process without excess sludge production. Water Sci. Tech., 34 (4), 395-404 (10 pages).
Yasui, H.; Shibata, M., (1994). An innovative approach to reduce excess sludge production in the activated sludge process. Water Sci. Tech., 30 (9), 11-20 (10 pages).

Yeom, I. T.; Lee, K. R.; Ahn, K. H.; Lee, Y. H.; Lee, S. H., (2002). Effects of ozone treatment on the biodegradability of sludge from municipal wastewater treatment plants. Water Sci. Tech., 46 (4-5), 421-425 (5 pages).

Yoon, S. H.; Kim, H. S.; Lee, S. H., (2004). Incorporation of ultrasonic cell disintegration into a membrane bioreactor for zero sludge production. Process Biochem., 39 (12), 19231929 ( 7 pages).

Young, K. O.; Lee, K. R.; Kwang, B. K.; Yeom, I. T., (2007). Effects of chemical sludge disintegration on the performances of wastewater treatment by membrane bioreactor. Water Res., 41 (12), 2665-2671 (7 pages).

Zhang, X. X.; Zhao, D. Y.; Wang, Z. X.; Wu, B.; Li, W. X.; Cheng, S. P., (2009). Environmental biological model based on optimization of activated sludge process. Int. J. Environ. Sci. Tech., 6 (1), 69-76 (8 pages).

\section{AUTHOR (S) BIOSKETCHES}

Rajesh banu, J., M.Sc., M.Phil., Ph.D., Assistant Professor, Environmental Science, Department of Civil Engineering, Anna University of Technology Tirunelveli, Tamilnadu, India. Email: rajeshces@gmail.com

Uan, D. k., Ph.D., Lecturer, Hanoi University of Technology, Vietnam and research scholar in Sungkyunkwan University, Korea. Email: dokhacuan@yahoo.com

Kaliappan, S., BE, M. Tech., Ph.D., Professor, Department of Civil Engineering and Vice-Chancellor of Anna University of Technology Tirunelveli, Tamilnadu, India. Email:drkalsun@yahoo.com

Yeom, I. T., Ph.D., is a Professor, Department of Civil and Environmental Engineering, Sungkyunkwan University and Director of Zero Emission Center, Korea. Email: yeom@skku.edu

How to cite this article: (Harvard style)

Rajesh banu, J.; Do Khac Uan; Kaliappan, S.; Yeom, I-T., (2011). Effect of sludge pretreatment on the performance of anaerobic/anoxic/ oxic membrane bioreactor treating domestic wastewater. Int. J. Environ. Sci. Tech., 8 (2), 281-290. 